\title{
Pulmonary arterial hypertension masquerading as severe refractory asthma
}

\author{
L. Achouh*, D. Montani*, G. Garcia*, X. Jaïs*, A.M. Hamid*, O. Mercier*, \\ G. Simonneau* and M. Humbert*
}

ABSTRACT: Once the diagnosis of pulmonary arterial hypertension is established, wheezing and chronic cough are rarely described during the course of the disease.

The present study reports on two nonsmoking patients with severe pulmonary arterial hypertension, confirmed by right-heart catheterisation, who developed chronic cough, wheezing and irreversible obstructive lung disease masquerading as adult-onset severe refractory asthma.

In both cases, extrinsic proximal airway obstruction by dilated pulmonary arteries was demonstrated by fibreoptic bronchoscopy and computed tomography of the chest.

The present observations add dilatation of the central pulmonary arteries with compression of the mainstem bronchi to the list of masqueraders of asthma in patients with pulmonary arterial hypertension.

KEYWORDS: Asthma, compression of the mainstem bronchi, congenital heart diseases, obstructive airway disease, Ortner's syndrome, pulmonary arterial hypertension

$\mathbf{P}$ ulmonary arterial hypertension (PAH) is a severe condition characterised by a progressive remodelling of small pulmonary arteries leading to elevated pulmonary vascular resistance and right ventricular failure. Despite several studies showing asymptomatic airway obstruction in patients with PAH [1, 2], asthmalike symptoms have been rarely reported during the course of the disease $[3,4]$. The present study reports on two nonsmoking patients with severe $\mathrm{PAH}$, confirmed by right-heart catheterisation, who developed cough, wheezing and irreversible obstructive lung disease masquerading as adultonset severe refractory asthma. In both cases, extrinsic proximal airway obstruction by dilated pulmonary arteries was demonstrated by fibreoptic bronchoscopy and computed tomography of the chest. The present observations add dilatation of the central pulmonary arteries with compression of the mainstem bronchi to the list of masqueraders of asthma in patients with $\mathrm{PAH}$.

\section{CASE 1}

A 34-yr-old nonsmoking male was referred to the present authors' institute in July 2002 for management of PAH. He had no personal or familial history of allergy, rhinitis, asthma, wheeze or chronic cough. At 3 yrs of age, he underwent a mesenterico-caval shunt for a portal cavernoma, and a diagnosis of mild PAH was made at 16 yrs of age. PAH-specific therapy was not initiated at that time. In 2002, the subject was in functional class III of the New York Heart Association (NYHA) classification and his 6-min walk distance (6MWD) was $580 \mathrm{~m}$ with a Borg index of dyspnoea of 3 . Mean pulmonary arterial pressure $(\bar{P}$ pa) was $52 \mathrm{mmHg}$, cardiac index (CI) was $3.84 \mathrm{~L} \cdot \mathrm{min}^{-1} \cdot \mathrm{m}^{-2}$, indexed total pulmonary resistance (RiTR) was $13.5 \mathrm{mmHg} \cdot \mathrm{L}^{-1} \cdot \mathrm{min}^{-1} \cdot \mathrm{m}^{-2}$, and mixed venous oxygen saturation $\left(\mathrm{SV}, \mathrm{O}_{2}\right)$ was $75 \%$. Pulmonary artery wedge pressure was normal and there was no acute vasodilator response to inhaled nitric oxide (NO). Pulmonary function tests (PFTs) showed irreversible obstructive lung disease: forced expiratory volume in one second (FEV1) was $2.29 \mathrm{~L}$ (52\% predicted); forced vital capacity (FVC) was 3.48L (65\% pred); FEV1/FVC ratio was 57\%; residual volume (RV) was $3.07 \mathrm{~L}(162 \%$ pred); total lung capacity (TLC) was 7.07 L (94\% pred); and the RV/TLC ratio was $162 \%$ (fig. 1a). Blood gases showed mild hypoxaemia (arterial oxygen tension $\left(\mathrm{Pa}_{2} \mathrm{O}_{2}\right)$ of $\left.10.7 \mathrm{kPa}\right)$ and hypocapnia (arterial carbon dioxide tension $\left(\mathrm{Pa}_{\mathrm{a}} \mathrm{CO}_{2}\right)$ of $3.95 \mathrm{kPa}$ ). Computed tomography of the chest showed significant dilatation of the pulmonary arteries. Medical treatment was initiated with warfarin and bosentan, a dual endothelin receptor antagonist. Regular monitoring demonstrated

\section{AFFILIATIONS}

*Université Paris-Sud 11, Centre National de Référence de L'Hypertension Artérielle Pulmonaire, Service de Pneumologie et Réanimation Respiratoire, Hôpital Antoine-Béclère, Clamart, and \#Université Paris-Sud 11, Service de Chirurgie Thoracique, Centre Chirurgical Marie-Lannelongue, Le Plessis-Robinson, France.

CORRESPONDENCE

M. Humbert

Service de Pneumologie et

Réanimation Respiratoire Hôpital Antoine-Béclère

157 rue de la Porte de Trivaux 92140 Clamart

France

Fax: 33146303824

E-mail: marc.humbert@abc.aphp.fr

Received:

January 132008

Accepted after revision: March 282008

\section{SUPPORT STATEMENT}

This study was supported in part by grants from Ministère de

L'Enseignemant Supérier et de la Recherche and the Université ParisSud 11.

STATEMENT OF INTEREST None declared. 
good clinical and haemodynamic response until 2004, when the patient presented with an acute episode of wheezing upon exertion and a chronic dry cough. Asthma was clinically suspected. There was no atopy on skin prick tests. PFTs confirmed irreversible airway obstruction but neither inhaled steroids nor bronchodilators improved respiratory symptoms or lung function (fig. 1a). Pulmonary haemodynamics and 6MWD remained stable. However, there was a marked deterioration in dyspnoea with a Borg index of 5 and audible wheezing during exercise. Computed tomography of the chest showed a thrombosed aneurysm of the proximal pulmonary arteries with bronchial compression (fig. 1b). Fibreoptic bronchoscopy revealed significant stenosis of the right mainstem bronchus and difficulty advancing the bronchoscope. A diagnosis of bronchial compression by massively dilated proximal pulmonary arteries was established. In June 2006, the patient was hospitalised for an acute myocardial infarction due to extrinsic stenosis of the left main coronary artery, without evidence of other coronary artery disease. This was consistent with a diagnosis of left coronary arterial extrinsic compression by the aneurysmal pulmonary arteries. In the context of worsening dyspnoea due to bronchial compression, along with coronary compression and myocardial infarction, the patient was listed for heart-lung transplantation and subsequently transplanted (fig. 2). Examination of the explanted lungs showed major bilateral dilatation of the proximal pulmonary arteries and a thrombosed aneurysm of the right pulmonary artery with severe small vessel pulmonary plexiform arteriopathy. No atherosclerotic coronary lesions were found. There was no bronchial inflammation or remodelling suggestive of asthma.
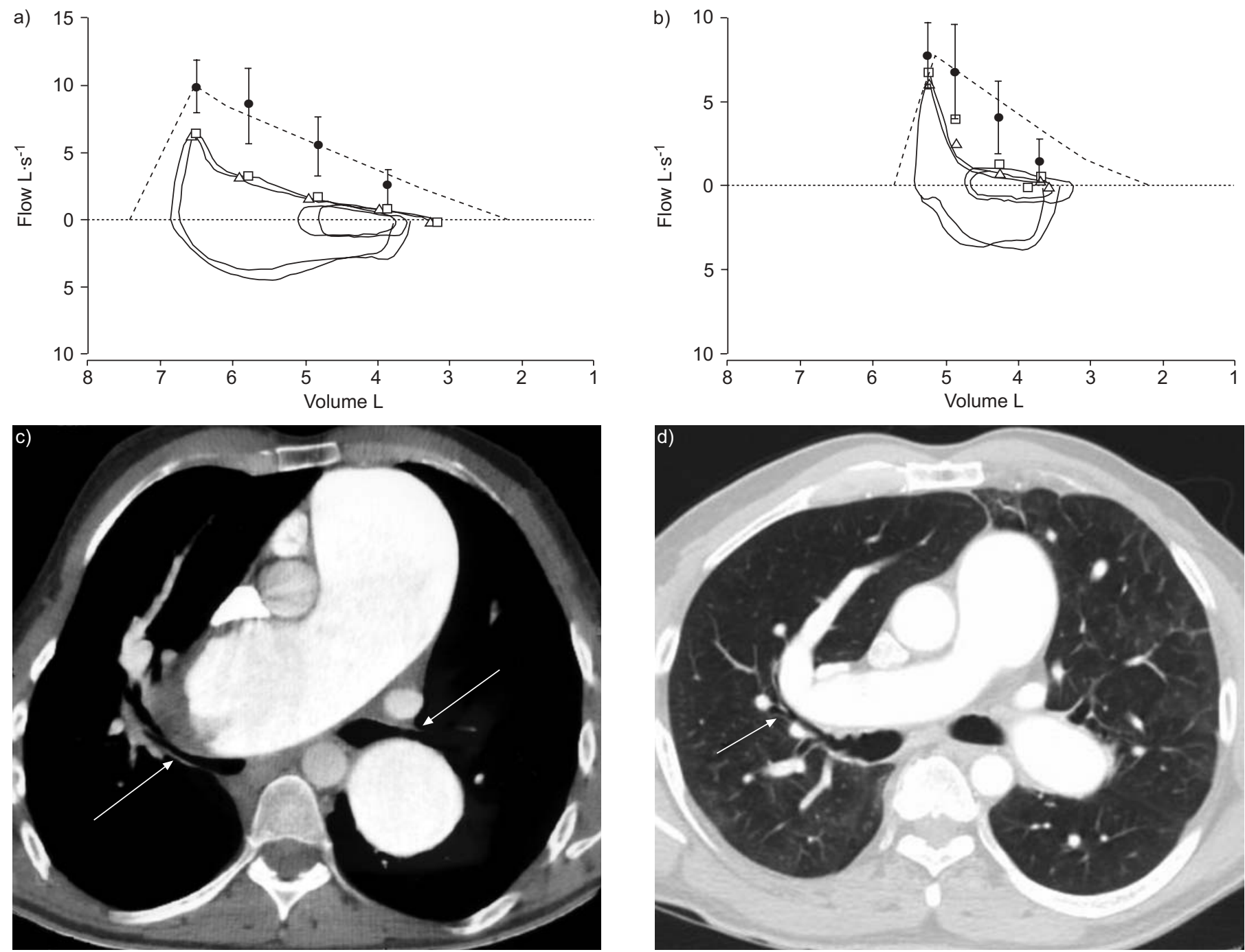

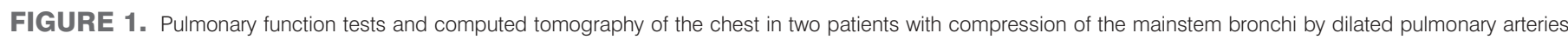

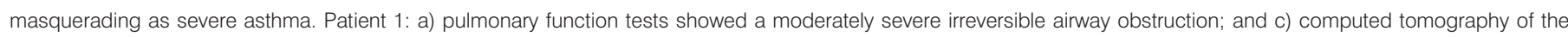

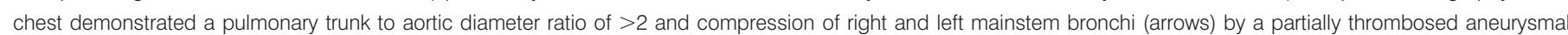

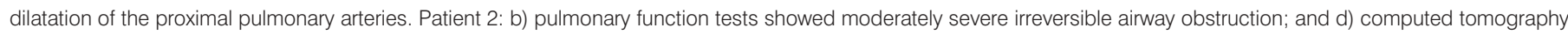

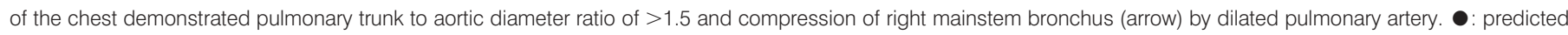
theoretical values presented as median $\mathrm{SSD}$; $\square$ : pre-bronchodilator values; $\triangle$ : post-bronchodilator values; - - -: \% predicted flow-volume; $\cdots . .$. : $0 \mathrm{~L} \cdot \mathrm{S}^{-1}$ flow. 

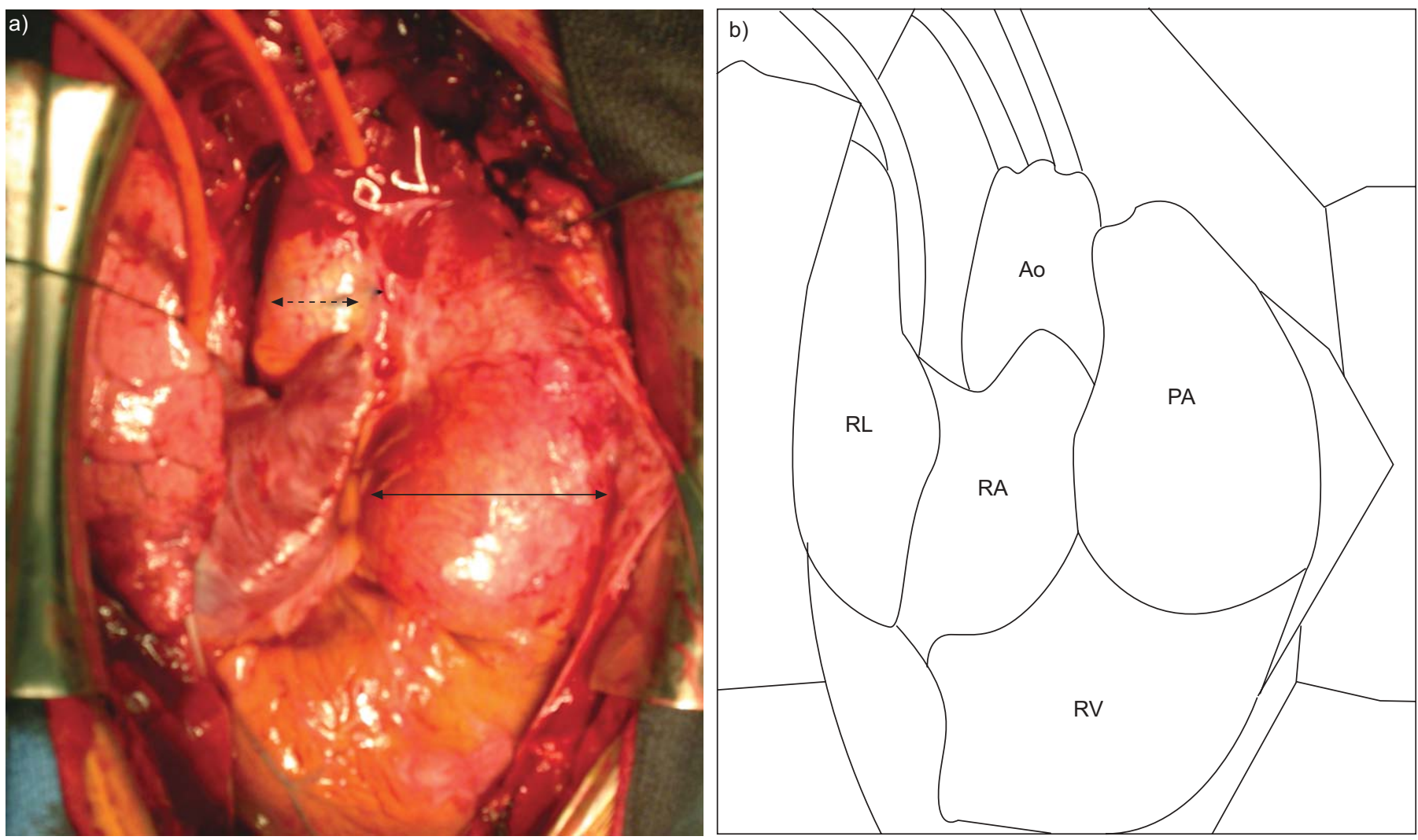

FIGURE 2. a) Operative view and b) schematic representation of patient 1 at the time of heart-lung transplantation showing major pulmonary artery dilatation (arrow) which is more than twice as large as the aorta (dotted arrow) Ao: aorta; PA: pulmonary artery; RA: right atrium; RL: right lung; RV: right ventricle.

\section{CASE 2}

A 56-yr-old nonsmoking male with PAH related to an atrial septal defect was referred to the present authors' institute in December 2001. He had no personal or familial history of allergy, rhinitis, asthma, wheeze or chronic cough. He was in NYHA functional class III and had a 6MWD of $450 \mathrm{~m}$ with a Borg index of dyspnoea of 1 . Haemodynamic evaluation revealed severe precapillary pulmonary hypertension, $\bar{P}_{\text {pa }}$ was $60 \mathrm{mmHg}, \quad \mathrm{CI}$ was $2.29 \mathrm{~L} \cdot \mathrm{min}^{-1} \cdot \mathrm{m}^{-2}$, RiTR was $14.5 \mathrm{mmHg} \cdot \mathrm{L}^{-1} \cdot \mathrm{min}^{-1} \cdot \mathrm{m}^{-2}, \mathrm{SV}, \mathrm{O}_{2}$ was $82 \%$ and there was a $36 \mathrm{~mm}$ atrial septal defect with bidirectional shunting. Pulmonary artery wedge pressure was normal and there was no acute vasodilator response to inhaled NO. PFTs showed a restrictive and obstructive pattern: FEV1 was $1.24 \mathrm{~L}(43 \%$ pred); FVC was $1.72 \mathrm{~L}$ (47\% pred); FEV1/FVC ratio was $72 \%$; TLC was $4.19 \mathrm{~L}$ (72\% pred); RV was $2.11 \mathrm{~L}$ (101\% pred); and $\mathrm{RV} / \mathrm{TLC}$ was $143 \%$. Blood gases showed hypoxaemia $\left(\mathrm{Pa}_{2} \mathrm{O}_{2}\right.$ of $8.55 \mathrm{kPa})$ and hypocapnia $\left(\mathrm{Pa}_{1} \mathrm{CO}_{2}\right.$ of $\left.4.25 \mathrm{kPa}\right)$. Computed tomography of the chest showed marked dilatation of the pulmonary arteries. Bosentan therapy was initiated, and regular monitoring demonstrated good clinical and haemodynamic response until 2005. In April 2005, he complained of chronic cough and wheezing especially upon exertion. Asthma was again clinically suspected. There was no atopy on skinprick tests. PFTs showed irreversible airway obstruction but neither inhaled steroids nor bronchodilators improved respiratory symptoms or lung function (fig. 1c). Pulmonary haemodynamics were stable, although there was a decline in 6MWD with a worse Borg index of dyspnoea of 3 and audible wheezing on exercise. After 6 months, he complained of hoarseness and underwent flexible bronchoscopy, which showed reduced mobility of the left vocal cord, compatible with Ortner's syndrome (cardiovocal syndrome) due to left recurrent laryngeal nerve palsy. In addition, there was an extrinsic compression of the right mainstem bronchus. Computed tomography of the chest showed bilateral bronchial compression, predominantly of the right mainstem bronchus, by dilated proximal pulmonary arteries (fig. 1d).

\section{DISCUSSION}

The present observations add dilatation of the central pulmonary arteries and compression of the mainstem bronchi to the list of masqueraders of late-onset asthma in patients with severe PAH. When airflow obstruction is irreversible, as it was in the present patients, an alternative diagnosis to asthma should be sought. Interestingly, both patients developed other symptoms due to compression by dilated proximal pulmonary arteries, including hoarseness (left recurrent laryngeal nerve palsy) [5] and myocardial infarction (extrinsic compression of the left main coronary artery) [6-8]. In patients with $\mathrm{PAH}$ complicating congenital heart diseases, compression by enlarged pulmonary arteries is common; narrowing of the left main coronary artery by extrinsic compression may be detected in $44 \%$ of patients with atrial septal defects [9] and in $26 \%$ of patients with pulmonary trunk to aortic diameter ratios $\geqslant 1.21$ [10]. 
Extrinsic airway compression may explain chronic cough, wheezing and obstructive lung disease in $\mathrm{PAH}$ patients. In that setting, it is useful to perform computed tomography of the chest, fibreoptic bronchoscopy and magnetic resonance imaging [11-13]. Interestingly, computed tomography of the chest has demonstrated pulmonary arteries that were consistently enlarged and could be aneurysmal, causing bronchial compression and atelectasis in patients with PAH associated with congenital heart diseases [14, 15].

Although wheezing and chronic cough are uncommon in PAH patients, several studies have demonstrated small airways disease in PAH. RASTOGI et al. [1] found distal small airway obstruction in $59 \%$ of paediatric $\mathrm{PAH}$ cases with no prior history of asthma or atopy, and a bronchodilator response was seen in $78 \%$ of patients with an obstructive baseline pattern. The FEV1/FVC ratio is inversely correlated with $\bar{P}_{\mathrm{pa}}$, whereas RV, TLC and the RV/TLC ratio positively correlated with $\bar{P}$ pa. SPIEKERKOETTER et al. [16] found a normal FEV1 in all patients with idiopathic PAH, whereas flow-volume curves, mean expiratory flow at $50 \%$ and $25 \%$ of vital capacity (MEF50\% and MEF25\%, respectively) showed peripheral airflow obstruction. In a cross sectional study of 171 adult patients with idiopathic PAH, MEYER et al. [2] demonstrated peripheral airway obstruction with a reduced FEV1/FVC, end-expiratory airflow limitation and moderate lung hyperinflation. RV/TLC ratio correlated with $\bar{P}_{\text {pa }}$ and was more elevated in patients with a $\bar{P}_{\text {pa }}>56 \mathrm{mmHg}$. Due to the proximity of the small pulmonary arteries and the peripheral airways, it was suggested that peripheral airway obstruction may reflect structural bronchial changes secondary to the underlying pulmonary vascular disease. In favour of this hypothesis, FERNANDEZ-BONETTI et al. [17] showed peripheral airway obstruction and narrowing of the small airways with thickened walls, infiltrated by lymphocytes, plasma cells and polymorphonuclear leukocytes, on lung samples from pulmonary arterial hypertension patients. However, it remains unclear whether small airway obstruction in $\mathrm{PAH}$ is the consequence of mechanical distal airway compression by remodelled small pulmonary arteries, structural airway abnormalities related to $\mathrm{PAH}$ or to the vasoconstrictive/bronchoconstrictive mediator imbalance characteristic of PAH (decreased NO and increased endothelin-1 production).

In summary, chronic cough, wheezing and obstructive airway disease may complicate the course of pulmonary arterial hypertension. These asthma-like symptoms are refractory to usual asthma therapy, such as steroids and bronchodilators, and may be due to compression of the mainstem bronchi by dilated pulmonary arteries. The present authors conclude that pulmonary arterial hypertension should be added to the list of conditions masquerading as severe refractory asthma.

\section{REFERENCES}

1 Rastogi D, Ngai P, Barst RJ, Koumbourlis AC. Lower airway obstruction, bronchial hyperresponsiveness, and primary pulmonary hypertension in children. Pediatr Pulmonol 2004; 37: 50-55.
2 Meyer FJ, Ewert R, Hoeper MM, et al. Peripheral airway obstruction in primary pulmonary hypertension. Thorax 2002; 57: 473-476.

3 Rothman A, Kulik TJ. Pulmonary hypertension and asthma in two patients with congenital heart disease. Am J Dis Child 1989; 143: 977-979.

4 Miller WW, Park CD, Waldhausen JA. Bronchial compression from enlarged, hypertensive right pulmonary artery with corrected transposition of great arteries, dextrocardia, and ventricular septal defect. Diagnosis and surgical treatment. J Thorac Cardiovasc Surg 1970; 60: 233-236.

5 Mulpuru SK, Vasavada BC, Punukollu GK, Patel AG. Cardiovocal syndrome: a systematic review. Heart Lung Circ 2008; 17: 1-4.

6 Fujiwara K, Naito Y, Higashiue S, et al. Left main coronary trunk compression by dilated main pulmonary artery in atrial septal defect. Report of three cases. I Thorac Cardiovasc Surg 1992; 104: 449-452.

7 Patrat JF, Jondeau G, Dubourg O, et al. Left main coronary artery compression during primary pulmonary hypertension. Chest 1997; 112: 842-843.

8 Kawut SM, Silvestry FE, Ferrari VA, et al. Extrinsic compression of the left main coronary artery by the pulmonary artery in patients with long-standing pulmonary hypertension. Am J Cardiol 1999; 83, 984-986: A10.

9 Mitsudo K, Fujino T, Matsunaga K, et al. [Coronary arteriographic findings in the patients with atrial septal defect and pulmonary hypertension (ASD + PH) compression of left main coronary artery by pulmonary trunk]. Kokyu To Junkan 1989; 37: 649-655.

10 Mesquita SM, Castro CR, Ikari NM, Oliveira SA, Lopes AA. Likelihood of left main coronary artery compression based on pulmonary trunk diameter in patients with pulmonary hypertension. Am J Med 2004; 116: 369-374.

11 Lee SL, Cheung YF, Leung MP, Ng YK, Tsoi NS. Airway obstruction in children with congenital heart disease: assessment by flexible bronchoscopy. Pediatr Pulmonol 2002; 34: 304-311.

12 Donnelly LF, Strife JL, Bailey WW. Extrinsic airway compression secondary to pulmonary arterial conduits: MR findings. Pediatr Radiol 1997; 27: 268-270.

13 Ditchfield MR, Culham JA. Assessment of airways compression by MR imaging in children with aneurysmal pulmonary arteries. Pediatr Radiol 1995; 25: 190-191.

14 Perloff JK, Hart EM, Greaves SM, Miner PD, Child JS. Proximal pulmonary arterial and intrapulmonary radiologic features of Eisenmenger syndrome and primary pulmonary hypertension. Am J Cardiol 2003; 92: 182-187.

15 Chaudry G, MacDonald C, Adatia I, Gundogan M, Manson D. CT of the chest in the evaluation of idiopathic pulmonary arterial hypertension in children. Pediatr Radiol 2007; 37: 345-350.

16 Spiekerkoetter E, Fabel H, Hoeper MM. Effects of inhaled salbutamol in primary pulmonary hypertension. Eur Respir J 2002; 20: 524-528.

17 Fernandez-Bonetti P, Lupi-Herrera E, Martinez-Guerra ML, Barrios R, Seoane M, Sandoval J. Peripheral airways obstruction in idiopathic pulmonary artery hypertension (primary). Chest 1983; 83: 732-738. 